\title{
Teoria do sujeito, geografia e desenvolvimento local
}

Xavier Arnauld de Sartre - Pesquisador no Centre National de la Recherche Scientifique, Laboratório Société, Environnement Territoire.

Vincent Berdoulay - Professor da Universidade de Pau et des Pays de l'Adour. Laboratório Société, Environnement, Territoire. Institut de Recherche sur les Sociétés et l'Aménagement (Irsam).

\section{Resumo}

O artigo aborda o estatuto teóricometodológico do desenvolvimento local relevando a necessidade de dar conta da noção de sujeito. As perspectivas do neo-estruturalismo e o acionismo são examinadas e destaca-se a abordagem que considera o sujeito inseparável de seu lugar. As reflexões focalizam a região da Transamazônica.

\section{Abstract}

The article approaches the theoreticmethodological statute of the local development, revealing the needs of showing the subject notion. The perspectives of neo-structuralism and actionism are examined and highlight the approach that consider the subject inseparable from its place. The reflections focus on the Transamazonia region.

\section{Palavras-chave}

desenvolvimento local, sujeito, neoestruturalismo, acionismo, lugar, rodovia Transamazônica

\section{Keywords}

local development, subject, neostructuralism, actionism, place, Transamazonic road 
O desenvolvimento local aparece hoje no centro de várias preocupações científicas e profissionais, pois o estatuto do local mudou. De simples território passivo, que recebe ações e políticas concebidas no seu "interesse" num nível superior, tornou-se a condição - ou uma das condições - para o surgimento de um espaço onde se produz um encontro gerador de desenvolvimento em todas as escalas (ARNAULD DE SARTRE; BERDOULAY, 2005).

Foi a partir dos anos 70 do século XX que o interesse pelo desenvolvimento local começou a se difundir, em particular no Quebec, na França e em vários países onde ele aparece sob outras designações, entre as quais, desenvolvimento comunitário (HICKS, 1961; HOUÉE, 1974; MEISTER, 1977; TAYLOR; STOHR, 1981; PECQUEUR, 1989; COSTA, 1996). Além da sua rápida inserção nos programas de ensino, o desenvolvimento local surge como uma possibilidade de expressão das insatisfações produzidas pelo desenvolvimento racional ou tecnocrático. Tratava-se de um planejamento pensado por profissionais que se imaginavam como os únicos detentores do saber pertinente, da verdade, e que não precisavam consultar as populações locais para decidir sobre o que seria bom para elas.

A abordagem racional havia se modificado no sentido de tornarse menos brutal. Por exemplo, o projeto de desenvolvimento é proposto ao longo de um processo no final do qual algumas correções são possíveis. Trata-se de uma abordagem incremental na qual a participação é instituída convidando a população local no momento da apresentação do projeto (a participação limita-se à discussão de algumas pequenas modificações no que já foi decidido). Mas, fundamentalmente, a abordagem é a mesma: o planejador legitima-se como um expert, que se legitima por sua vez pela "verdade científica". Caso a população não siga o que lhe foi proposto, há então necessidade de se comunicar com ela, explicar o porquê do projeto, que de qualquer forma não pode ser modificado.

O movimento que representa o desenvolvimento local aparece como uma reação, uma resistência às práticas anteriores. Tanto foi o seu vigor que ele caiu, às vezes, nos excessos inversos. Assim, insistindo-se na vontade de agir levando em conta as escolhas das populações, de agir de baixo para cima ao invés de cima para baixo, o local chegou a ser considerado como uma verdade impossível de criticar. Chegou-se até, às vezes, a desconsiderar a existência de interesses comuns. A crítica do planejamento de cima para baixo chegou também a ser uma crítica da noção de desenvolvimento, que reduz os problemas às suas únicas dimensões econômicas ou produtivistas. A crise ambiental, notadamente 
na escala mundial, fez renascer as preocupações acerca do desenvolvimento sustentável.

No fundo, os temas que saíram desses debates e que ainda são pertinentes têm a ver com a autonomia do local, com a democracia local ou com a cultura local. São impregnados pelos conhecimentos e pelas práticas. A exigência contemporânea de democracia somente reforçou essas pretensões e legitimou-as. Assim, no decorrer do tempo, o desenvolvimento local constituiu uma preocupação cada vez mais aberta às pessoas, ao papel delas. Há menos preocupação com um indivíduo passivo do que com um sujeito autônomo e ativo que quer dominar as condições da sua vida individual ou coletiva. Há interesse por um sujeito que assume seu próprio destino.

Embora essa abordagem seja importante no âmbito da retórica, das aspirações, ela mal consegue traduzir-se em uma modificação profunda das teorias e dos modelos de ação que podem ser mobilizados para entender ou favorecer o desenvolvimento local. As inovações recentes na organização do debate público não chegaram a esse nível, tanto como a abordagem colaborativa, apesar da sua vontade de instituir a inteira participação das populações atingidas por um projeto e de fazer com que o profissional seja mais um mediador do que um técnico que concebe os projetos (SOUBEYRAN; BARNIER, 1985; COELHO; FONTES, 1995; BERDOULAY, 2003). O fato de insistir nos procedimentos não permite levar em conta o que, fundamentalmente, motiva os sujeitos.

Parece óbvio que o desenvolvimento local constitui-se à margem das pesquisas fundamentais das ciências humanas e sociais, sem dúvida porque havia uma preocupação com a eficiência imediata e com a profissionalização. A ação de desenvolvimento local faz-se pelo uso de procedimentos, de técnicas, de diagnósticos de identificação dos jogos de atores, etc. Ela baseia-se em uma metodologia que, no fundo, faz pensar na frieza dos processos aos quais se opunha, pois todas essas técnicas são pouco sensíveis à experiência do sujeito, ou pelo menos pouco a assimilam.

Há um desafio que precisa ser enfrentado. Em nossa contribuição para isso, postulamos como ponto de partida o seguinte: o movimento acima evocado, que corresponde à demanda de desenvolvimento local para melhor levar em conta os sujeitos, recebe um eco semelhante nas ciências humanas e sociais contemporâneas, mesmo que elas não tenham numa perspectiva fundamental, preocupação imediata com a ação.

Embora seja na maioria dos casos confusa e incompleta, a integração da perspectiva do sujeito no foco das abordagens das ciências hu- 
manas e sociais corresponde a um tema muito debatido. Podemos até dizer que essa preocupação com o sujeito está crescendo hoje em dia. É uma verdadeira revolução epistemológica que está acontecendo, cujas dimensões ainda são desconhecidas. Ela nos lembra da necessidade de melhor entender a noção de sujeito, numa perspectiva disciplinar, interdisciplinar e transdisciplinar, pois o seu impacto atinge até as demandas de enquadramento da ação no planejamento e desenvolvimento local.

Uma das dificuldades tem a ver, talvez, com o peso do estruturalismo, que ainda era forte nas ciências humanas e sociais na época da emergência do desenvolvimento local. Apesar desse quadro teórico terse mostrado inadequado para descrever os fenômenos de desenvolvimento local, não houve um acompanhamento das experiências e investimento científico suficiente para desenvolver um outro quadro teórico. Entre o neo-estruturalismo de Bourdieu (1980) e o acionismo de Boudon (1979), a abertura que o desenvolvimento local deu à questão do sujeito pouco se traduz numa modificação das suas bases teóricas e metodológicas.

Quando o estruturalismo começou a declinar, a análise das estruturas (simbólicas, sociais, econômicas ou até naturais) deixou de ser percebida como a única chave de compreensão, e as ciências humanas e sociais buscaram um lugar maior no voluntarismo do ator, nas suas estratégias individuais e coletivas. Ao mesmo tempo, a subjetividade das populações foi estudada enquanto representação, mas sem que essa subjetividade fosse articulada diretamente à ação e à transformação do mundo.

Há aí vários passos importantes. Pode-se considerar que o neoestruturalismo foi essencial: enquanto se dizia com freqüência que o problema com as populações locais é que elas se opunham às mudanças por causa das suas tradições ou da falta de conhecimento, demonstrou-se que são esquemas de pensamento (estruturas mentais) que determinam a ação e a inovação. Mas um dos problemas desse tipo de abordagem é considerar que há bloqueios, religiosos ou estruturais, que determinam a inovação: institui-se, então, um determinismo social que, simplificado como é muitas vezes o caso nos manuais de desenvolvimento, leva a considerar que a mudança é impossível.

Uma outra abordagem, que se identifica não com o determinismo, mas com o acionismo, traduz também esse conjunto teórico que se firmou depois da abordagem estruturalista - sem conseguir, por enquanto, dar à luz um campo autônomo e coerente. O livro do J. P. Olivier de Sardan (1995), representativo dessa tentativa, tem tal vontade: decla- 
rando-se actor-oriented, a exemplo de um outro autor dessa escola, Norman Long (1977), Olivier de Sardan reconhece que as estruturas não podem ser suficientes para explicar os comportamentos observados; seu objetivo é entender quais podem ser as estratégias que os atores adotam em alguns contextos particulares.

A abordagem actor-oriented é uma reação ao estruturalismo: trata-se de considerar que os atores têm razões racionais, embora essa racionalidade seja entendida num sentido vago. J. P. Olivier de Sardan (1995, p. 32) escreve:

embora as racionalidades camponesas sejam diferentes das que postulam os atores do desenvolvimento ou das do homo economicus das teorias neo-liberais, sua racionalidade é econômica, e podemos entendê-las sem invocar os famosos bloqueios culturais ou os obstáculos religiosos.

Trata-se de considerar, como é o caso na teoria sistêmica, que os atores têm razões, e boas razões, para fazer o que fazem. Assim, esses autores, mostrando o papel ativo das populações na recepção e na elaboração de uma política de desenvolvimento, falam de racionalidades e, rapidamente, de estratégias: "o enfoque é posto nos atores sociais, ou nos grupos de atores sociais, nas estratégias e nos desafios deles. A liberdade dos indivíduos e dos grupos dentro dos limites definidos pelas estruturas acabou sendo agora um objeto de estudo privilegiado" (OLIVIER DE SARDAN, 1995, p. 39).

Essa abordagem quer ser uma síntese das estruturas que orientam a ação com as estratégias dos atores - o que J. P. Olivier de Sardan chama de estruturalismo: "a perspectiva interacionista aqui defendida pretende combinar a análise das obrigações e estratégias dos atores, o peso das estruturas e as dinâmicas individuais ou coletivas" (OLIVIER DE SARDAN, p. 40). A perspectiva é estratégica. Identifica-se nela o encontro de três abordagens: a sociologia das organizações (CROZIER; FRIEDBERG, 1997), a teoria do ator de Touraine (1984) e a teoria da estruturação de Giddens (1984).

A filiação às duas primeiras abordagens é evidente. Crozier e Friedberg desenvolveram sua teoria num quadro próximo do sistêmico, mas dando-lhe uma abertura maior. O sistema é aquele que atua para opor obrigações ao ator, para definir o quadro dentro do qual o ator, cuja racionalidade é limitada, atua e define suas estratégias. Touraine vai além, quando mostra que essas racionalidades podem ser múltiplas e situadas em vários contextos. Olivier de Sardan dedica várias páginas a esses temas. Assim, a idéia de "arena de desenvolvimento", aplicação 
muito comum da teoria de Olivier de Sardan, tem como objetivo mostrar que o desenvolvimento está preso a relações locais de poder, que precisam ser entendidas e que orientam a ação.

Porém, entende-se mais dificilmente a referência à teoria da estruturação de A. Giddens. Embora essa teoria pretenda realizar uma síntese da estrutura com o ator, situando-os em contextos particulares, essa síntese, ao contrário do que pretende Olivier de Sardan, vai além das estratégias, ou das racionalidades. Na teoria de Giddens, há uma certa consciência prática e uma certa "rotineirização" (regularidade) dos comportamentos, que não são unicamente estratégicos nem "não-conscientes" (segundo a expressão que usaria Bourdieu). Ela tem a ver com um saber tópico particular. É a chamada teoria do sujeito, longe da teoria do ator, à qual, finalmente, se refere J. P. Olivier de Sardan.

A vontade de levar em conta o sujeito enquanto ser autônomo e ativo vai além. O sujeito não é um indivíduo que realiza no seu comportamento lógicas exteriores a ele, lógicas que somente ele aplicaria (DUBET, 1994; TOURAINE, 1984). O sujeito deve compor com as contradições que essas lógicas geram em outros contextos. Ele deve assumir tensões, problemas, conflitos que lhe são impostos e construir assim as suas próprias trajetórias.

É aí que intervém particularmente a preocupação geográfica por meio das dimensões territoriais, ambientais, ecológicas, da consciência de si. Observa-se no mundo contemporâneo uma diversificação dos espaços de referência, dos espaços de pertinência cultural e social, a ponto de alguns acharem que o lugar não é mais uma realidade da vida social. Mas, constatando a mesma diversificação das referências, podese ter uma interpretação diferente (BERDOULAY; ENTRIKIN, 1998). Pode-se dizer que essa diversificação exige, na verdade, um investimento maior do sujeito: é ele que tem de dar uma coerência a seu próprio mundo e, portanto, a sua identidade. A pluralidade do sujeito responde à multiplicidade dos espaços de referência: o sujeito constrói no seu próprio mundo um lugar que é o dele e que é coerente.

O que mostram os trabalhos contemporâneos não é uma justaposição de esferas separadas, mais ou menos combinadas, mas uma abordagem que considera o sujeito enquanto inseparável de seu lugar. Sujeito e lugar são inseparáveis: um não existe sem o outro (BERDOULAY, 1997). É essa visão geográfica do sujeito e do lugar que nos convida a revisitar os espaços nos quais o sujeito está inserido. No contexto atual de aspirações democráticas, isso parece ainda mais justificado, observando-se importantes transformações geopolíticas. 
Estamos procurando novos lugares de enunciação para decidir sobre nosso futuro. A noção de sujeito - transdisciplinar - deve ser inscrita no espaço e no tempo: ela deve permitir perceber melhor os lugares de enunciação em que eles mesmos podem gerar desenvolvimento local.

Nossa vontade de enriquecer o ponto de vista do desenvolvimento local pela abordagem do sujeito tal como está sendo feita nas ciências humanas e sociais contemporâneas não é uma mitificação da escala local. Com efeito, a evolução das idéias pós-estruturalistas nessas ciências não leva à legitimação de uma abordagem na qual o local estaria investido de uma verdade primária ou superior que invocamos acima. Duas razões, no mínimo, militam contra esse unilateralismo, infelizmente muito comum no campo do desenvolvimento local. A primeira é que não se deve "jogar o bebê com a água do banho"! Existem saberes profissionais em planejamento, desenvolvimento, que são úteis, ainda que tenham de ser transformados, modificados etc. A segunda razão é que, entre a localidade e o planeta inteiro, há uma multiplicidade de escalas espaciais, territoriais ou interconectadas por redes, que têm uma influência tanto na construção e no futuro dos sujeitos e dos lugares como na identificação profissional dos problemas e das soluções elaboradas. O desenvolvimento local leva, antes de qualquer coisa, a um meio ambiente que não é o objeto a ser modificado, mas o meio pelo qual o desenvolvimento é possível. Deve-se lembrar que esse meio ambiente é composto também por tudo aquilo de que a cultura e o imaginário dispõem para fazer do indivíduo um sujeito.

No fundo, queremos mostrar que a perspectiva geográfica do sujeito não é só uma preocupação teórica e epistemológica, quer dizer, longe da ação prática e concreta. Poderíamos, para mostrar isso, estudar o exemplo das preocupações recentes com o desenvolvimento na Amazônia, em particular na região da Transamazônica.

A Amazônia tem sido um dos lugares no mundo onde as práticas modernistas de desenvolvimento e de uso incontrolado da natureza aplicaram-se com a maior força. Já foi discutida a pouca preocupação dos grandes projetos com as populações locais, com o espaço e com as populações que servem a sua política (CARDOSO GALANT, 2005). A única lógica desses grandes projetos é a da modernidade científica e desenvolvimentista, apenas alterada pelos objetivos do Estado e dos grupos que têm influência nele. Ora, ainda que essa confrontação de modernidade e de arcaísmo tenha uma forte presença na Amazônia, observa-se, desde o início dos anos 90, tentativas para transformá-la. 
Não se deve ao acaso o fato de a educação ser hoje uma das ferramentas privilegiadas pelos atores de desenvolvimento.

Na região de Altamira, nas margens da Transamazônica, o chamado Movimento pela Sobrevivência da Transamazônica (MPST) nasceu no final dos anos 80 como uma reação das populações locais ao que chamavam de abandono da Transamazônica: após a colonização pública nos anos 70, a região parecia abandonada pelas políticas públicas. No decorrer do tempo, o MPST estruturou-se e chegou a ser um ator incontestável na região: um deputado federal, um deputado estadual, o vice-prefeito de Belém, o presidente da Central Única dos Trabalhadores (CUT), vários prefeitos, vice-prefeitos e vereadores da Transamazônica foram ou são membros do MPST. Essa importância maior que o movimento assumiu na região levou a uma mudança de nome: foram estruturadas duas entidades, uma chamada Movimento pelo Desenvolvimento da Transamazônica e do Xingu (MDTX), que tem um papel mais político, e outra denominada Fundação Viver Produzir Preservar (FVPP), voltada para o desenvolvimento.

Esse movimento chegou até a propor um modelo de desenvolvimento regional que é uma reação contra o desenvolvimento modernista que tradicionalmente caracteriza a Transamazônica. Quando se opôs ao projeto de construção da barragem de Belo Monte, o MDTX agiu em nome do que podemos entender como desenvolvimento local:

Esse tipo de obra não combina com os padrões de desenvolvimento apropriados para a região. A modernidade na Amazônia significa ganhar dinheiro e gerar oportunidades de negócios lucrativos com o uso racional das florestas, dos rios, dos solos e dos subsolos. A construção de projetos que destroem essas riquezas e esses estoques de capital são [sic] pouco inteligentes e estão na contramão da modernidade na região e no país. [...]

Exigimos que nosso projeto de desenvolvimento sustentável para a região da Transamazônica, que tem por base a agricultura familiar, criação e uso de reservas florestais, verticalização da produção, fomento à educação e eletrificação rural, trafegabilidade dos travessões e da rodovia Transamazônica, demarcação e proteção das terras indígenas e a viabilização de alternativas economicamente sustentáveis para as comunidades ribeirinhas e indígenas, seja discutido e viabilizado imediatamente pelos ministérios do Meio Ambiente, Ministério da Justiça, Planejamento, Orçamento e Gestão e Integração Nacional, assim como Ministério Público e Agência Nacional de Águas, Governo do Estado e Ibama.

O Projeto dos movimentos sociais da região, denominado "Fortalecimento da Produção Familiar e Contenção dos Desmatamentos da Transamazônica e Xingu", elaborado em vinte anos de resistência nessa 
região, é um ponto de partida para a discussão de um macrozoneamento responsável por uma área que envolve 13 municípios, definindo rumos para um desenvolvimento em bases democráticas. Inclusive, corrigindo vários erros do projeto de colonização como a estrutura fundiária (MOVIMENTO PELO DESENVOLVIMENTO DA TRANSAMAZÔNICA E DO XINGU, 2001).

É claramente um projeto de desenvolvimento local o que os membros do MDTX propõem, em oposição às políticas modernas do Estado. Essa reivindicação pode ser entendida com o quadro teórico da sociologia do desenvolvimento: trata-se do reconhecimento de uma organização sindical e associativa enquanto ator do desenvolvimento e da sua capacidade de orientar as políticas no sentido dos seus interesses. Trata-se de formar e ao mesmo tempo demarcar o território desse conjunto de associações e de impô-lo aos atores públicos clássicos. O quadro teórico que permite fazer esse estudo é o clássico, do estruturalismo. Por isso, o MDTX formula um projeto de desenvolvimento regional e exige que ele seja financiado. Mas a vontade do MDTX vai além dessa política: para que esse território tivesse uma realidade que fosse além da simples marca política, deveria ser reconhecido pelas populações locais, e essas populações deveriam ser sujeitos ativos do desenvolvimento da região - e não simples espectadores. É por essa razão que um dos eixos fortes do projeto acima citado - "Fortalecimento da Produção Familiar e Contenção dos Desmatamentos da Transamazônica e Xingu" - é a educação rural. Foi o primeiro eixo do programa do MDTX a ser financiado, e ainda é o mais importante do conjunto. A educação rural está pensada como uma educação destinada aos filhos de agricultores familiares e voltada para o mundo rural. A educação por alternância das Casas Familiares Rurais (CFR), iniciada na França, foi o modelo de educação rural escolhido pelos atores do desenvolvimento voltado para o mundo rural.

A observação do funcionamento dessas escolas e a realização de entrevistas semi-estruturadas com monitores e representantes do MDTX ou das CFR, por ocasião de uma pesquisa sobre a mobilidade camponesa (ARNAULD DE SARTRE, 2003a), mostraram que essas escolas querem facilitar a emergência de um sujeito capaz de refletir sobre a sua própria condição e de usar o meio ambiente sem destruí-lo. Há divergências, claro, quanto ao papel que essas escolas deveriam assumir, na visão de cada ator que participa desse projeto, mas essas divergências, que às vezes levam a verdadeiras crises, não se refletem numa ruptura com os anseios dos atores participantes do projeto das CFR de que es- 
sas escolas ajudem no surgimento de um "sujeito" (ver a análise de Ribeiro (2003)). O coordenador do MDTX em 2001, Bruno Klempner, chamava esse sujeito de cidadão:

Então são todas essas ações [...] por exemplo eu mesmo aqui digo que nós não temos direito de amarrar o jovem na roça, tem que dar o direito a cidadania dele para ele poder escolher também o que quer para ele. Será que ele quer permanecer na roça? Ele tem condições de permanecer. Se ele tem um outro sonho, ele pode [...] é o grande desafio da gente, fazer como essa escola seja para um cidadão.

Permitindo que o jovem escolha a sua trajetória, o coordenador do MDTX quer que ele seja capaz de refletir sobre a sua condição. Esse tipo de ação estava muito presente no funcionamento quotidiano das CFR: os alunos eram convidados a esse tipo de reflexão, a tal ponto que se pode dizer que essas ações têm o objetivo de conscientizar os jovens. Essa perspectiva, evidentemente, é diretamente herdada das práticas impulsionadas por Paulo Freire (1970), cujo objetivo, ao alfabetizar trabalhadores, ia além da formação: era uma vontade de emancipação individual e social, usando a prática para a elaboração do saber teórico. Mas esse objetivo foi reformulado nas CFR, que pensam que a conscientização "só é possível, em primeiro lugar, a partir da compreensão da educação como um fator de mudança sociocultural e, em segundo lugar, da efetivação de um currículo contextualizado a partir de um movimento social e cultural mais amplo, perseguindo a construção de sujeitos sociais e políticos" (RIBEIRO; SILVA, 2005). As experiências de educação rural na Transamazônica, como as da região de Marabá das quais falam Ribeiro e Silva, querem permitir a emergência desse sujeito. No sentido dos atores do desenvolvimento, trabalhar com sujeitos é uma necessidade para alcançar, a longo prazo, os seus objetivos.

Ora, esse objetivo corresponde a mudanças que já estão acontecendo na Transamazônica e podem ser aceleradas: observa-se um processo de subjetivação entre os jovens agricultores da região Transamazônica. Se os pais desses jovens, os colonos da Transamazônica, podem ser identificados como camponeses (ARNAULD DE SARTRE, 2003b) caracterizados por lógicas sobretudo tradicionais, segundo a tipologia de Max Weber -, seus filhos não podem mais ser considerados como camponeses (ARNAULD DE SARTRE, 2005): com efeito, os filhos querem ter um controle sobre a sua vida diferente da maneira como os pais deles controlaram a própria vida. Estudando-se as principais etapas da vida de um camponês, percebe-se que os jovens querem ter um contro- 
le sobre essas etapas, não querem reagir por obediência a uma tradição: após sair da escola, querem trabalhar com os pais somente se estes últimos lhes derem uma "verdadeira condição"; antes de casar, querem viver a sua "mocidade", fazendo experiências inéditas; no momento de casar, querem escolher o(a) esposo(a) por amor; depois de casados, querem decidir quantos filhos terão (e querem poucos filhos) (ARNAULD DE SARTRE, 2002).

Mas, sobretudo, eles querem que essa vida aconteça no lugar que eles escolheram, pela qualidade de vida e pelas amizades que têm. Enquanto seus pais migraram várias vezes antes de chegar à Transamazônica, migrações em busca de terra para instalar sua família, os jovens não querem migrar a qualquer preço: embora o fato de ir para uma área de colonização nova permita conseguir terras, muitos jovens preferem assalariar-se, ou ficar como agricultores trabalhando em áreas pequenas, a ter de migrar. A explicação que eles dão não é somente uma oposição às condições de vida que terão nesse lugar, mas também o fato de gostarem da região onde cresceram e têm a família. A identificação com um lugar de vida é um dos fatores mais importantes da emergência do sujeito.

É importante salientar que esse processo não é generalizado. Há jovens que estão dispostos a migrar quando aparecer uma oportunidade, pois o processo de subjetivação não tem a mesma força sobre todos os jovens. Ora, os jovens que estão mais avançados nesse processo são os que estudaram nas Casas Familiares Rurais. O texto seguinte é a transcrição do início da entrevista com um jovem que estudou na CFR de Medicilândia e que depois foi morar um tempo numa cidade de Minas Gerais, antes de voltar para o lote dos seus pais:

Jovem: No começo, como não conhecia bem as coisas, o meu pensamento era só ficar aqui mesmo. Porque como não conhecia as coisas de fora [...] Aqui é assim, nunca ninguém se separou de casa; só tem um que casou e esse outro que saiu, mas os outros sempre foram unidos dentro de casa. Eu gosto daqui, aí fiz essa viagem e mudei a cabeça um pouco [...] eu vim de lá porque era o jeito, meu irmão quebrou a perna. Precisava de mim. Mas eu tenho um pensamento bom de ficar aqui. Estudei na CFR, eu aprendi muita coisa. No momento, apliquei quase nada em casa, também é difícil a condição financeira da gente [...] para ver mesmo o que foi feito é pouca coisa. Aí o pensamento [...] bom, eu tenho um pensamento firme, de ficar aqui, principalmente com os meninos agora, parece que eles mudaram, nem só eu, mas mudou tudo, é mais organizado, apesar de que ainda falta muita coisa [...] é o jeito da gente, espero conseguir muita coisa [...] 
Pesquisador: Você está pensando em ficar aqui nesse lote? Jovem: É, o meu pensamento é aqui, né. Quando cheguei, pensava muito de voltar para Minas, para morar lá, só que é ilusão da gente, é um lugar bom aqui [...] Para se trabalhar, não trabalhar assim só com os braços, a gente aprende muita coisa, tem que ter muito planejamento, saber administrar [...] senão, tem que mudar [...]

Pesquisador: Quer dizer planejar?

Jovem: Planejamento assim, com a família: o que a gente vai fazer, por exemplo se faz isso daí será que vai dar certo, se vai ter rendimento [...] a gente mesmo aqui, está com 31 anos parece que mora aqui, até hoje posso dizer que tem quase nada. O que tem foi feito assim... não foi uma coisa pensada assim, se vai dar certo. De agora para frente, principalmente depois que eu fui para CFR, aprendi muita coisa, como trabalhar, só que ainda é difícil, tem que colocar em prática mas não tem aquela condição [...] mas estamos indo para frente, igual o criadouro de abelha, a gente pegou, vai levantando [...] tem outras coisas aí que a gente vai levar para frente.

No itinerário desse jovem, a CFR aparece como um momento central. No início dessa entrevista, esse jovem diz que foi o fato de ter viajado para fora da região que mudou suas perspectivas; ele opõe a sedentariedade dos irmãos, que tem como conseqüência a falta de perspectiva e o fato de ficar na região por costume, à sua mobilidade, que lhe permitiu escolher o lugar onde mora. O processo de saída da agricultura está relacionado com a concorrência entre a vida na Transamazônica e a vida numa cidade de Minas: era como se a saída da agricultura fosse a conseqüência do confronto entre a tradição, representada pela vida no lote, e a modernidade das cidades. Mas o que fez com que ele ficasse na região foi o fato de ter estudado na CFR: é por meio da CFR que ele se deu conta de que a vida na região era possível e interessante. A CFR mostrou-lhe que tinha uma alternativa entre a modernidade da cidade e a vida tradicional na zona rural, que podia encontrar uma "modernidade alternativa" na Transamazônica. A CFR ajudou a criar um sujeito em ligação com o seu lugar, a Transamazônica.

Esse exemplo mostra o quanto uma experiência de desenvolvimento local, que pode ser analisada como uma vontade política de demarcar o território de um grupo político (o MDTX), precisa, na verdade, da emergência de sujeitos capazes de refletir sobre sua própria situação e de escolher o seu lugar de morada para alcançar os objetivos de desenvolvimento rural que eles fixam para si. O território do sindicalismo camponês precisa de sujeitos que o reconheçam: deve ser ao mesmo tempo o território de um conjunto de associações e o lugar de sujei- 
tos. A noção de sujeito requer que se lance um olhar diferente sobre o desenvolvimento local e sobre o território, para melhor ligá-lo às preocupações profundas que caracterizam a nossa época. O exemplo que acabamos de descrever mostra que isso é verdade até numa região profundamente marcada pelo desenvolvimento moderno, onde o peso das estruturas sociais e espaciais é particularmente forte, acompanhado de violências muitas vezes institucionalizadas. Mas é justamente por meio dos problemas e dos desafios enfrentados pelos especialistas do desenvolvimento local que se pode ver que a preocupação com o sujeito não é um luxo para intelectuais; constitui uma base essencial na qual se assentam as ações de desenvolvimento local.

Quando falamos de local, e quando pretendemos agir nessa escala, precisamos compreender os laços que unem o local aos sujeitos. Eles dão ao local um sentido particular, a partir do qual os sujeitos fundam as suas experiências quotidianas. É dessa base que o desenvolvimento local pode (re)partir. 


\section{REFERÊNCIAS}

ARNAULD DE SARTRE, Xavier. Entre condição de agricultor e profissão: reproduções e construções sociais de jovens agricultores duma frente pioneira amazônica. In: CONGRÈS LATINO-AMÉRICAIN DE SOCIOLOGIE RURALE, SUSTENTABILIDAD Y DEMOCRATIZACIÓN DE LAS SOCIEDADES RURALES LATINOAMERICANAS, 6., 2002, Porto Alegre. Anais... Porto Alegre, 2002. 1 CD-ROM.

. Territorialités contradictoires des jeunes ruraux amazoniens: mobilités paysannes ou sédentarités professionnelles? 2003. Tese de doutorado - Universidade de Toulouse le Mirail, Toulouse, 2003a.

- Agricultures familiales de front pionnier amazonien: la sédentarisation en question. Natures Sciences Sociétés, Nanterre, v. 11, n. 2, p. 158-168, 2003b.

. Modernité et développement durable: le cas de l'agriculture familiale en situation de front pionnier amazonien. Espaces et Sociétés, Paris, n. 120, p. 221-239, 2005.

ARNAULD DE SARTRE, Xavier; BERDOULAY, Vincent. Le développement local dans la perspective du sujet géographique. Hégoa, Pau, v. 25, p. 5-14, 2005.

BERDOULAY, Vincent. Le lieu et l'espace public. Cahiers de Géographie du Québec, Montréal, v. 41, p. 301-309, 1997.

Desarrollo sostenible y organización del debate público: reflexiones sobre experiencias norteamericanas de evaluación ambiental. Nuevos territorios para nuevas sociedades, Zaragoza, CIOT, v. 4, p. 59-64, 2003.

BERDOULAY, Vincent; ENTRIKIN, J. Nicholas. Lieu et sujet: perspectives théoriques. L'Espace Géographique, Montpellier, v. 27, n. 2, p. 75-89, 1998.

BOUDON, Raymond. La Logique du social. Paris: Hachette, 1979. 333p.

BOURDIEU, Pierre. Le sens pratique. Paris: Editions de Minuit, 1980. 477p. (Collection Le sens commun).

CARDOSO GALANT, Francinete. Les savoirs et les lieux des sujets sociaux amazoniens dans la soutenabilité environnementale. Hégoa, Pau, n. 25, p. 
65-73, 2005.

COELHO, Franklin; FONTES, Angela (coord.). Guia de orientação para o desenvolvimento econômico local. Rio de Janeiro: IBAM/Fundação Frederich Ebert/SEBRAE, 1995.

COSTA, João Bosco Araújo. A ressignificação do local: o imaginário político brasileiro pós-80. Revista São Paulo em Perspectiva, São Paulo, v. 10, n. 3, 1996

CROZIER, Michel; FRIEDBERG, Erhard. L'acteur et le système. Paris: Seuil, 1977.

DUBET, François. Sociologie de l'expérience. Paris: Seuil, 1994.

FREIRE, Paulo. Pedagogia do oprimido. São Paulo: Paz e Terra, 1970.

GIDDENS, Anthony. La constitution de la société: éléments de la théorie de la structuration. Paris: Presses Universitaires de France, 1984.

HICKS, U.K. Development from below. Oxford: Clarendon Press, 1961.

HOUÉE, Paul. Quel avenir pour les ruraux? Paris: Les Éditions ouvrières, 1974.

LONG, Norman. An introduction to the sociology of rural development. Londres and New York: Tavistock, 1977.

MEISTER, Albert. La participation pour le développement. Paris: Les Éditions ouvrières, 1977.

MOVIMENTO PELO DESENVOLVIMENTO DA TRANZAMAZÔNICA E DO XINGU. SOS Xingu: um chamamento ao bom senso sobre o represamento de rios na Amazônia. Altamira, Pará, 25 jul. 2001.

OLIVIER DE SARDAN, Jean-Pierre. Anthropologie et développement: essai en socio-anthropologie du changement social. Marseille: Coédition Karthala-APAD, 1995.

PECQUEUR, Bernard. Le développement local. Paris: Syros, 1989.

RIBEIRO, Beatriz M. F. Viver, produzir e preservar: construindo o Projeto Casa Familiar Rural da Transamazônica (1980-2002). 2003. 186f. Dissertação (Mestrado em Planejamento do Desenvolvimento) - Núcleo de Altos Estudos Amazônicos, Universidade Federal do Pará, Belém, 2003. 
RIBEIRO, Beatriz M. F.; SILVA, Marizete F. da. La pédagogie de l'alternance se fait dans l'action. Hégoa, Pau, v. 25, p. 33-44, 2005.

SOUBEYRAN, Olivier; BARNIER, Véronique. Les enjeux du virage aménagiste. Loisirs et société, v. 8, p. 55-91, 1985.

TAYLOR, D. R. F.; STOHR, W. (coord.). Development from above or development from below? Radical approaches to spatial planning in developing countries. Chichester: Wiley, 1981.

TOURAINE, Alain. Le retour de l'acteur. Paris: Fayard, 1984.

Critique de la modernité. Paris: Fayard, 1992. 